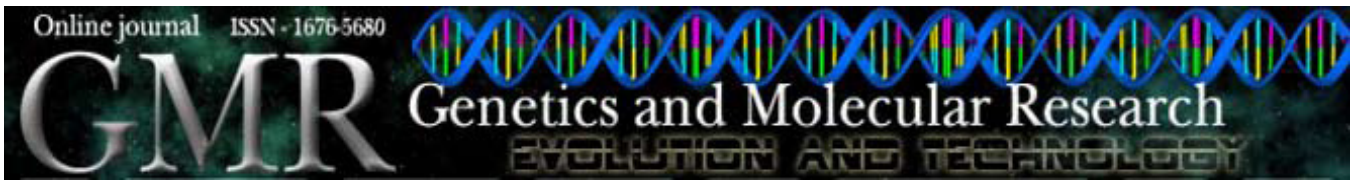

\title{
Analysis of p53 codon 72 gene polymorphism in Brazilian patients with endometriosis
}

\author{
C.L. Ribeiro Júnior ${ }^{1,2 *}$, J.T. Arruda ${ }^{3 *}$, C.T.X. Silva ${ }^{3}$ and \\ K.K.V.O. Moura ${ }^{2,3}$ \\ ${ }^{1}$ Centro de Medicina Fetal e Reprodução Humana - FÉRTILE, Goiânia, GO, Brasil \\ ${ }^{2}$ Programa de Pós-Graduação Stricto Sensu, Mestrado em Genética, \\ Goiânia, GO, Brasil \\ ${ }^{3}$ Departamento de Biologia, Núcleo de Pesquisas Replicon, \\ Universidade Católica de Goiás, Goiânia, GO, Brasil \\ *These authors contributed equally to this study. \\ Corresponding author: K.K.V.O. Moura \\ E-mail: kkverolli@ucg.br, katiakarinav@yahoo.com.br
}

Genet. Mol. Res. 8 (2): 494-499 (2009)

Received February 3, 2009

Accepted March 13, 2009

Published May 5, 2009

\begin{abstract}
We examined the frequency of p53 codon 72 polymorphism in 38 patients with endometriosis whose diagnosis was confirmed using videolaparoscopy. Half of the women were infertile. There were no significant differences in the genotype $(\mathrm{P}=$ $0.0927)$ or allele frequencies $(\mathrm{P}=0.1430)$ for p53 Arg72Pro polymorphism between the two groups. We found a significant association between the heterozygous and homozygous proline genotypes and intense pain in the patients. Sixty-four percent of the patients were homozygous or heterozygous for proline in patients with degree III or IV endometriosis, but there was no significant difference compared to homozygous arginine genotype $(\mathrm{P}=0.6115)$. We found that the proline allele is associated with substantial complaints (infertility associated with pain), when compared to the homozygous arginine genotype; we also found that the proline allele
\end{abstract}


was more frequent in endometriosis patients.

Key words: p53 gene; Endometriosis; Codon 72 polymorphism

\section{INTRODUCTION}

Endometriosis is a polygenic and multifactorial disease that is characterized by the growth of endometrial tissue outside the uterine cavity and that frequently results in various gynecologic problems, including dyspareunia, dysmenorrhea, pelvic pain, and infertility (Bischoff and Simpson, 2000). Although approximately 18\% of women of childbearing age develop the disease (Wieser et al., 2002), its etiology still remains obscure. The theory of retrograde menstruation has been widely utilized to explain its origin. This theory proposes that during reflux of menstrual fluid, viable endometrial cells are shed in menstruation and reach the peritoneal cavity via the uterine tubes, with consequent implantation and local growth, since peritoneal macrophages of patients with endometriosis are not capable of efficiently phagocytizing the peritoneal reflux (Santanam et al., 2002; Seli et al., 2003).

Studies have demonstrated a familial tendency for the occurrence of endometriosis (dos Reis et al., 1999; Simpson and Bischoff, 2003), which in association with the interaction of multiple genes as well as environmental factors determines the occurrence of the disease (Bischoff et al., 2002). Endometriosis exhibits characteristics similar to those of malignancy, such as local invasion and aggressive spreading to distant organs. Its monoclonal origin indicates a neoplastic and genetic nature in the majority of endometrial lesions (Nakayama et al., 2001; Melin et al., 2006).

Genomic alterations can represent important events in the development of endometriosis. The p53 is a tumor suppressor gene, controlling the regulation of cell growth and the regulation of the cell cycle, where it is involved in cell proliferation as well as the progression of various types of tumors. It is located on chromosome $17 \mathrm{p} 13$, and induces apoptosis or blocks the cell cycle in response to DNA damage, making it possible for cells to be destroyed or repaired before re-initiation of DNA replication (Robles et al., 2002). On the other hand, germline variants of the p53 gene are less known, and there are controversies over their importance in various tumors (Storey et al., 1998; Zehbe et al., 2001; Koushik et al., 2004).

Two variants described in p53 codon 72 gene derive from the substitution of a single nucleotide resulting in the presence of proline (p53pro) or arginine (p53arg) in the protein product. Studies have reported the arginine homozygote in codon 72 as being a risk factor for the development of cancer (Storey et al., 1998), while others revealed an elevated risk in individuals with the proline homozygous genotype (Wang et al., 1999; Yu et al., 1999).

Mutation of p53 has been found in endometriosis (Bischoff et al., 2002). Abnormalities and chromosomal aberrations related to p53 can be associated with the malignant transformation of ovarian endometriosis (Mhawech et al., 2002). Some investigators did not detect altered expression of p53 in endometriosis (Horiuchi et al., 1998; Schneider et al., 1998).

The aim of this study was to determine the frequency of $\mathrm{p} 53$ codon 72 polymorphism in patients with endometriosis and other symptoms of the disease. 


\section{MATERIAL AND METHODS}

\section{Patients}

The study included 38 peripheral blood samples of patients ( 25 to 35 years old) from a reference center for videolaparoscopy and infertility in Goiânia, Brazil (FERTILE); the patients had signs and symptoms suggestive of endometriosis and had been submitted to videolaparoscopy for clarification of diagnosis and treatment. All patients had a diagnosis of endometriosis confirmed by a pathologist. The patients answered a questionnaire on personal information and social habits and were divided into two groups of 19 each. Group I comprised women who complained of infertility and who had intentions of pregnancy with a history of trying for at least one year. The women in group II already had children without any difficulties or assisted reproduction, but they had other complaints or an ultrasound examination suggesting endometriosis. On videolaparoscopy, the patients were classified with regard to the degree of endometriosis, based on the criteria defined by the American Fertility Society (then called the American Society for Reproductive Medicine; Anonymous, 1997): grade I (minimal), grade II (slight), grade III (moderate), grade IV (severe), and based on a tubal patency test, where the injection of methylene blue makes it possible to determine if there is permeability of the Fallopian tubes. The exclusion criteria were: patients submitted to salpingectomy (tubal factor); partner with two abnormal semen analyses (male factor); persistent anovulation diagnosed by ultrasound (ovarian factor), and abnormal post-coitus test (cervical factor).

\section{Molecular analysis}

Genomic DNA was extracted from peripheral blood with the Illustra ${ }^{\mathrm{TM}}$ Blood Genomic DNA kit (GE HealthCare, USA). In the analysis for $\mathrm{p} 53$ gene codon 72 polymorphism, the primer Pro-72 (F-5'-GCCAGAGGCTGCTCCCCC-3' and R-5'-CGTGCAAGTCACA GACTT-3') was designed for $\mathrm{p} 53$ codon 72 in the proline form and Arg-72 (F-5'-TCCCCCT TGCCGTCCCAA and R-5'-CTGGTGCAGGGGCCACGC), according to the procedure described by Lattuada et al. (2004). The polymerase chain reaction products were loaded onto a $2 \%$ agarose gel containing ethidium bromide for electrophoresis. After electrophoresis, the gels were stained with ethidium bromide and photographed under UV light (Image Master VDS - Amersham Pharmacia Biotech, USA).

Statistical analysis for the relative risk of p53 codon 72 in the two groups was compared using the $\chi^{2}$ test and odds ratio (OR) for the determination of possible associations between molecular results and clinical and histopathologic data. The results were considered to be significant when the probability of findings occurring by chance was less than $5 \%(\mathrm{P}<0.05)$.

\section{RESULTS}

There was no statistically significant difference both in the genotype and allele frequencies for p53 Arg72Pro polymorphism between the patients with endometriosis in the groups analyzed (Table 1). The two groups with endometriosis showed similar genotype and allele frequencies for the $\mathrm{p} 53 \mathrm{Arg} 72 \mathrm{Pro}$ polymorphism. 


\begin{tabular}{|c|c|c|c|}
\hline & Group I & Group II & \\
\hline \multicolumn{4}{|l|}{ Allele } \\
\hline Arginine & $0.76 \%(29)$ & $0.57 \%(22)$ & \multirow[t]{2}{*}{$\mathrm{P}=0.1430$} \\
\hline Proline & $0.23 \%(9)$ & $0.42 \%(16)$ & \\
\hline \multicolumn{4}{|l|}{ Genotype } \\
\hline \multicolumn{4}{|l|}{ Codominant model } \\
\hline Arg-Arg & $52.64 \%(10)$ & $21.06 \%$ & \multirow[t]{3}{*}{$\mathrm{P}=0.0911$} \\
\hline Arg-Pro & $47.36 \%(9)$ & $73.68 \%(14)$ & \\
\hline Pro-Pro & 0 & $5.26 \%(1)$ & \\
\hline \multicolumn{4}{|l|}{ Dominant model } \\
\hline Arg-Arg + Arg-Pro & $100 \%(19)$ & $94.74 \%(18)$ & \multirow[t]{2}{*}{$\mathrm{P}=1.0000$} \\
\hline Pro-Pro & 0 & $5.26 \%(1)$ & \\
\hline \multicolumn{4}{|l|}{ Recessive model } \\
\hline Arg-Arg & $52.64 \%(10)$ & $21.06 \%$ & \multirow[t]{2}{*}{$\mathrm{P}=0.092$} \\
\hline Arg-Pro + Pro-Pro & $47.36 \%(9)$ & $78.94 \%(15)$ & \\
\hline
\end{tabular}

Data are reported as percent with number of individuals in parentheses.

When correlating the pain as light/moderate or moderate in groups with the polymorphism analyzed (arginine homozygous and proline heterozygous or homozygous), 92.85\% patients with a complaint of slight/moderate pain were arginine homozygous and $16.67 \%$ were proline homozygous or heterozygous. Whereas $7.15 \%$ of the patients with intense pain were arginine homozygous and $83.33 \%$ were proline homozygous or heterozygous. There was a statistically significant difference $(\mathrm{P}<0.001$ and $\mathrm{OR}=0.024(95 \% \mathrm{CI}=0.003$ to 0.222$))$. In the classification of endometriosis and correlation with polymorphism, $50 \%$ of patients arginine homozygous were classified in grade I, II, III, or IV, but $36.37 \%$ were proline homozygous or heterozygous in grade I or II and $63.63 \%$ in grade III or IV (Table 2).

Table 2. Correlation between pelvic pain intensity and classification of endometriosis and polymorphism.

\begin{tabular}{lcc}
\hline $\begin{array}{l}\text { Genotype } \\
\text { characteristics }\end{array}$ & $\begin{array}{c}\text { Arg-Arg } \\
\mathrm{N}(\%)\end{array}$ & $\begin{array}{c}\text { Arg-Pro or Pro-Pro } \\
\mathrm{N}(\%)\end{array}$ \\
\hline $\begin{array}{l}\text { Pain } \\
\text { Slight/moderate }\end{array}$ & $13(92.85 \%)$ & $4(16.67 \%)$ \\
Intense & $1(7.15 \%)$ & $20(83.33 \%)$ \\
Total & 14 & 24 \\
Classification* & $8(50 \%)$ & $8(36.37 \%)$ \\
Grade I or II & $8(50 \%)$ & $14(63.63 \%)$ \\
Grade III or IV & 16 & 22 \\
Total & & $\mathrm{P}=0.001$ \\
\hline
\end{tabular}

*Endometriosis classification was performed according to the American Society for Reproductive Medicine (Anonymous, 1997).

\section{DISCUSSION}

Endometriosis is a pathologic condition that involves abnormal endometrial cell adhesion, growth, and proliferation in ectopic tissues, such as the ovary and the peritoneal surface (Béliard et al., 2004). Studies of p53 codon 72 polymorphism with respect to the incidence of endometriosis have been controversial. 
In a Chinese population, Chang et al. (2002) reported an association between the proline form and endometriosis and suggested a protective action of the homozygous Arg-Arg genotype against the disease. The association has been confirmed in a Taiwanese (Hsieh and Lin, 2006) but not in a Japanese population (Omori et al., 2004). According to these authors, the arginine homozygous genotype in codon 72 is related to low susceptibility for developing endometriosis, while the proline homozygous or heterozygous allele is related to higher susceptibility of developing the disease. In a recent study on the population of Milan, Italy, Lattuada et al. (2004) did not find such an association, but rather an increased incidence of the proline form in the more severe forms of the disease, as reported as well by Ammendola et al. (2008) in women of Rome, Italy.

We did not observe any significant difference in the distribution of the p53 codon 72 polymorphism between the groups $(\mathrm{P}=0.0974)$, only in patients with intense pain and the proline homozygous or heterozygous genotype $(\mathrm{P}<0.001)$. The proline allele is present in the more severe cases of endometriosis (pelvic pain associated with infertility) with more severe prognosis and difficult to treat. The proline form of $\mathrm{p} 53$ protein is a stronger activator of transcription but a poor activator of apoptosis, compared to the arginine form (Robles et al., 2002).

One major reason for controversy may be differences in ethnicity. Race-specific variation in the distribution of genotypes in the p53 codon 72 polymorphism has already been demonstrated. An ethnic difference in the frequency of the proline allele between populations can explain these differing results. Pena (2005) discussed the difficulty in our country of correlating any findings with ethnicity and the matter that factors such as socio-economic ones could influence the results presented. In Brazil, the influence of ethnicity is complicated by the fact that our population is miscegenated, and many investigators report white skin color as a phenotype, but the genotype is often not congruous with this phenotype. Since the patients in the present study were from a private clinic, a socio-economic factor could have influenced the results.

In conclusion, the presence of the proline allele is linked more to patients with infertility and with a more severe clinical picture of the disease. The $\mathrm{p} 53$ polymorphism could be used as a molecular marker for endometriosis associated with exacerbated symptoms and infertility, and therefore as a great aid in the diagnosis of endometriosis, guiding prognosis and treatment of this disease.

\section{ACKNOWLEDGMENTS}

Research supported by Universidade Católica de Goiás, Goiânia, Brazil (UCG/PROPE/ MGene). We are grateful to the Centro de Medicina Fetal e Reprodução Humana - FÉRTILE for allowing us to conduct this research and for support. J.T. Arruda was the recipient of a fellowship from Conselho Nacional de Desenvolvimento Científico e Tecnológico (CNPq).

\section{REFERENCES}

Ammendola M, Gloria-Bottini F, Sesti F, Piccione E, et al. (2008). Association of p53 codon 72 polymorphism with endometriosis. Fertil. Steril. 90: 406-408.

Anonymous (1997). Revised American Society for Reproductive Medicine classification of endometriosis: 1996. Fertil. Steril. 67: 817-821.

Béliard A, Noel A and Foidart JM (2004). Reduction of apoptosis and proliferation in endometriosis. Fertil. Steril. 82: 80-85.

Bischoff FZ and Simpson JL (2000). Heritability and molecular genetic studies of endometriosis. Hum. Reprod. Update 6: $37-44$. 
Bischoff FZ, Heard M and Simpson JL (2002). Somatic DNA alterations in endometriosis: high frequency of chromosome 17 and 53 loss in late-stage endometriosis. J. Reprod. Immunol. 55: 49-64.

Chang CC, Hsieh YY, Tsai FJ, Tsai CH, et al. (2002). The proline form of $\mathrm{p} 53$ codon 72 polymorphism is associated with endometriosis. Fertil. Steril. 77: 43-45.

dos Reis RM, de Sa MF, de Moura MD, Nogueira AA, et al. (1999). Familial risk among patients with endometriosis. J. Assist. Reprod. Genet. 16: 500-503.

Horiuchi A, Osada R, Nakayama K, Toki T, et al. (1998). Ovarian yolk sac tumor with endometrioid carcinoma arising from endometriosis in a postmenopausal woman, with special reference to expression of alpha-fetoprotein, sex steroid receptors, and p53. Gynecol. Oncol. 70: 295-299.

Hsieh YY and Lin CS (2006). P53 codon 11, 72, and 248 gene polymorphisms in endometriosis. Int. J. Biol. Sci. 2: 188-193.

Koushik A, Platt RW and Franco EL (2004). p53 codon 72 polymorphism and cervical neoplasia: a meta-analysis review. Cancer Epidemiol. Biomarkers Prev. 13: 11-22.

Lattuada D, Vigano P, Somigliana E, Abbiati A, et al. (2004). Analysis of the codon 72 polymorphism of the TP53 gene in patients with endometriosis. Mol. Hum. Reprod. 10: 651-654.

Melin A, Sparen P, Persson I and Bergqvist A (2006). Endometriosis and the risk of cancer with special emphasis on ovarian cancer. Hum. Reprod. 21: 1237-1242.

Mhawech P, Kinkel K, Vlastos G and Pelte MF (2002). Ovarian carcinomas in endometriosis: an immunohistochemical and comparative genomic hybridization study. Int. J. Gynecol. Pathol. 21: 401-406.

Nakayama K, Toki T, Zhai YL, Lu X, et al. (2001). Demonstration of focal p53 expression without genetic alterations in endometriotic lesions. Int. J. Gynecol. Pathol. 20: 227-231.

Omori S, Yoshida S, Kennedy SH, Negoro K, et al. (2004). Polymorphism at codon 72 of the p53 gene is not associated with endometriosis in a Japanese population. J. Soc. Gynecol. Investig. 11: 232-236.

Pena SDJ (2005). Razões para banir o conceito de raça da medicina brasileira. Hist. Cienc. Saúde Manguinhos 12: 321-346.

Robles AI, Linke SP and Harris CC (2002). The p53 network in lung carcinogenesis. Oncogene 21: 6898-6907.

Santanam N, Murphy AA and Parthasarathy S (2002). Macrophages, oxidation, and endometriosis. Ann. N. Y. Acad. Sci. 955: 183-198.

Schneider J, Jimenez E, Rodriguez F and del Tanago JG (1998). c-myc, c-erb-B2, nm23 and p53 expression in human endometriosis. Oncol. Rep. 5: 49-52.

Seli E, Berkkanoglu M and Arici A (2003). Pathogenesis of endometriosis. Obstet. Gynecol. Clin. North Am. 30: 41-61.

Simpson JL and Bischoff F (2003). Heritability and candidate genes for endometriosis. Reprod. Biomed. Online 7: 162-169.

Storey A, Thomas M, Kalita A, Harwood C, et al. (1998). Role of a p53 polymorphism in the development of human papillomavirus-associated cancer. Nature 393: 229-234.

Wang NM, Tsai CH, Yeh KT, Chen SJ, et al. (1999). P53 codon 72Arg polymorphism is not a risk factor for carcinogenesis in the Chinese. Int. J. Mol. Med. 4: 249-252.

Wieser F, Schneeberger C, Tong D, Tempfer C, et al. (2002). PROGINS receptor gene polymorphism is associated with endometriosis. Fertil. Steril. 77: 309-312.

Yu MW, Yang SY, Chiu YH, Chiang YC, et al. (1999). A p53 genetic polymorphism as a modulator of hepatocellular carcinoma risk in relation to chronic liver disease, familial tendency, and cigarette smoking in hepatitis B carriers. Hepatology 29: 697-702.

Zehbe I, Voglino G, Wilander E, Delius H, et al. (2001). p53 codon 72 polymorphism and various human papillomavirus 16 E6 genotypes are risk factors for cervical cancer development. Cancer Res. 61: 608-611. 